\title{
Chaozhou Guild Hall's Social Functions and Cohesiveness
}

\author{
Jingyin Xu \\ Faculty of English Language and Culture, Guangdong University of Foreign Studies, Guangzhou 510420, Guangdong, China \\ jingyinxu@163.com
}

\begin{abstract}
As one of the most eminent business groups in Chinese history, Chaoshan merchants have left footprints in a great many of places throughout the world and built up world-wide Chaozhou guild halls, sites with multiple functions range from supporting their countrymen, worshiping the gods in Chaoshan culture, dealing with commercial issues to holding many other activities that strengthen the cultural identity of the Chaoshan people. The historical sites can still be seen in Beijing, Shanghai, Suzhou, Guangzhou, Shantou, Hongkong and other cities in China as well as quantities of overseas districts. This essay will take some of the Chaozhou guild halls as research subject to examine how the buildings serve as social bond and how the social functions of the architectures are related to the cohesiveness. This essay argues that the construction of the Chaozhou guild halls root in Chaoshan people's idea of solidarity, but the power of intensifying Chanshan people's cultural identity lies heavily on the constructions'social functions, in that the daily life, decision, and action of Chaoshan merchants are made to associate with the place closely. Numerous historical events took place in the guild halls engage into historical progression, and the guilds halls evolved into the chamber of commerce after establishment of the People's Republic of China, which indicates the significance of looking at the historical architectures from the perspective of cultural studies.
\end{abstract}

Keywords: Chaozhou guild hall, Cultural identity, Chaoshan merchants, Cohesiveness, Chamber of commerce.

\section{Introduction}

Guild hall initially appeared in the Ming dynasty, and the first guild hall, Wuhu Guild Hall of Beijing, was constructed in 1421 under the instruction of Yu Mo, a Chinese officer whose hometown is Wuhu. The architecture was originally used as accommodation for the candidates who travelled a long distance to Beijing to take the Imperial Examination. In the Qing dynasty, three branch Chaozhou guild halls with this function were built up in Beijing because of the efforts Lin Deyong and his fellows made. Chaozhou assembly hall broadly refers to the site built by Chaoshan people for the use of countrymen gathering and dealing with relevant issues. Compared with the Chaozhou Guild Hall of Beijing that invested by the officers, the ones that developed much earlier are those constructed by the Chaoshan merchants, and one of the examples is Chaozhou Guild Hall of Suzhou appeared in 1682 (in the Ming dynasty) in Nanjing. During the budding period of capitalism in the Ming dynasty, some commercial bands rose in China, among which the Chaoshan merchants incline running business overseas and in the coastal cities in China, thus their culture is also called "Blue Culture". Chaoshan people mainly refer to those who come from Chaozhou, Shantou, Jieyang, Fengshun, Shanwei and other surrounding areas. Chanshan area is located in the southeast of Guangdong province, bordering Fujian province in the east, and facing the south China sea in the south. The development of Chaoshan area was late due to the terrain barrier, but after the water and land transportation was opened successively in the Tang and Song dynasties, the industrial and commercial economy in Chaoshan area developed rapidly. Since then, the footprints of Chaoshan merchants have reached most of the cities all over the world, and the events took place in the Chaozhou assembly halls engaged into historical progression, so it is of great importance to analyse the social functions and cohesiveness of the Chaozhou assembly halls, which regretfully attracts little attention. This essay will take some of the Chaozhou guild halls as research subject to examine how the buildings serve as social bond and how the social functions of the architectures are related to the cohesiveness. This essay argues that the construction of the Chaozhou guild halls root in Chaoshan people's idea of solidarity, but the power of intensifying Chanshan people's cultural identity lies heavily on the constructions' social functions, in that the daily life, decision, and action of Chaoshan merchants are made to associate with the place closely.

\section{Chaozhou Guild Halls in China and Their Social Functions}

After the middle of the Ming dynasty, a large number of assembly halls appeared, and the guild halls began to develop from simple fellow township organizations to industrial and commercial organizations and carried more functions. Take Chaozhou Guild Hall of Shanghai as example. It was founded in 1759, the 24th year of the governing of Emperor Qianlong, and it is located in Jinyangshuo road in Shanghai. In the main hall called "Mazu Hall", there is a plaque on the top of the door dedicated to Mazu, the lord of the sea in Chinese myth, which shows the characteristic of "the maritime merchant gang" (Guo 184). According to the constitution of the guild hall, "anyone who lives in Chaozhou and has a legitimate business in Shanghai can become a member of the association" (Zhang 257), the requirement for recruit is rather loose, which indicates various of Chaoshan businessmen could get together in the organization and the foundation is comparatively solid. It is recorded that in the late Southern Song dynasty and Yuan dynasty, Chaoshan people had entered Shanghai for running business by ship. However, after Zhu Yuanzhang, the first emperor of the Ming dynasty, implemented the policy of banning maritime business in the early Ming dynasty, due to the prohibition of offshore shipping, the Chaozhou merchants who came to Shanghai were basically cut off. After the reformation of the maritime policy in 1685, the 24th year of the reign of Emperor Kangxi of the Qing dynasty, merchant ships from Chaozhou began to enter Shanghai, and many Chaozhou people settled in Shanghai. As Chaozhou people have been doing business in other places for a long time, they 
know very well that the best way to protect themselves is to "set up a local people's organization" (Xue 1-2). Making a living in somewhere far away from their hometown triggers the Chaoshan people's desire to stay together with their countrymen, in that Confucian culture is the main component of Chaoshan culture which emphasizes "clan, blood relationship and geographical concept" (Long 63). The prosperity of Chaoshan guild halls all over the world also reflects Chaoshan businessmen's need to "seek for internal cohesion, centripetal force and identity" and their sense of belonging is "more prominent than other business groups" (Long 63). Importantly, the guild hall carries various of functions that bring the Chaoshan people in closer contact. One of the most significant social functions of the guild hall is to worship gods collectively. Chaoshan businessmen believe that the gods can help them if they worship the gods, which may result from the semi-closed environment and the dangers they usually encounter when they go to the sea. The gods that they worship in the guild is various because Chaoshan people have multiple gods. Besides, the guild hall also allows the fellow countrymen to tackle commercial disputes and maintain their interest. When the local commercial gang encounters difficulties in business activities, especially when the problem comes from the official oppression, the guild hall makes representations to safeguard the "legitimate" interests of the local commercial gang. Sometimes it also adjusts to stop the disputes within the commercial side. Chaozhou Guild Hall of Shanghai is often very active in maintaining the benefits of the rural commercial gang. For example, in 1913, the customs supervision and tax department reformed the original two-month limit of goods storage in the customs warehouse. Those who exceed the limit would be fined. This is a measure that seriously harms the interests of Chinese industry and commerce. After a series of struggles, the customs supervisor and the tax department finally "gave a definite concession" (Guo 190). The Chaozhou Guild Hall of Shanghai also charges public welfare, which includes many aspects, such as charity for the former township, relief aid for disasters and wars, donation to the former township's water resources construction and so on. In 1922, there was a devastating wind disaster, which causes more than 100000 people losing their lives. After receiving the news, the association decided to set up a disaster relief office, and five thousand yuan was sent to Shantou. The board also decided to "remit another 35000 yuan to Shantou" (Guo 191). All these increase the centripetal force of the guild hall and strengthen the Chaoshan people's cohesiveness. According to the constitution of the guild hall, the club aims to contact fellow villagers and deal with public welfare and charity affairs of fellow villagers, and it also charges purchasing villa as well as coffin and administering medicine. Nevertheless, the guild hall's social functions are beyond its principle listed in the constitution. The guild hall is also essential because of its function of helping the government to manage the transfer population. After Shanghai served as a treaty port, more and more immigrants came to the city to make a living, which increases the workload of the local government. Xiangrong, the imperial envoy at that time, reported to the imperial court that many immigrants in Chaozhou area had difficulties in making a living in the south of the Yangtze river, and they had to "make a living by escorting opium when they could not get food and clothing" (Pan 44). The guild hall then became an important place to deal with the fellows' issues, and it exerted influence on their daily life by the democratic conference. The democratic procedure of the Chaoshan conference, the situation of the chairman presiding over the meeting, the theme of the meeting, the speeches of the directors and the results of the meeting were recorded in the "record of the motions of Chaozhou assembly hall" and "the record of the case of the Chaozhou assembly hall", which are kept by Shanghai Municipal Archives Center (Guo 182). Chaozhou Guild Hall of Shanghai used to adopt the board of directors' system, with eight directors elected from eight cities, which is changed to the committee system in 1929. After the victory of the Anti-Japanese War, the system changes back to the board of directors' system. Any rich family who has the ability to raise public funds can serve as associate directors. Its election procedure basically adopts the modern parliamentary democracy. Those who are able to raise public funds are eligible for election. It can be seen that the management system and major decisions of Chaozhou guild hall are democratic. The development of the commercial economy itself called for democracy and equality, and it vigorously "attacked the feudal system" (Guo 188). The democratic procedure for dealing the Chaoshan people's issues promoting the development of the Chaoshan businessmen and serves as their shelter, which strengthens their sense of belongings and their sense of pride. This is also one of the reasons that the Chaozhou Guild Hall of Shanghai can exert such powerful influence for nearly two centuries (from 1759 to 1949). The importance of the guild hall also reflects in its functions of uniting the fellows to play their parts in important historical events. Take the guild hall's engagement into supporting Sun Yat-sen as example. In 1922, Chen Ming turned against Sun Yat-sen. Their struggle has led to a political split between local and foreign merchants. For example, Chen's army raised funds in Chaoshan area, which made the merchants suffer from losing numerous donation, and the Chaozhou Guild Hall of Shanghai made repeated correspondence and teleport negotiations in vain. The guild hall then took Sun Yat-sen's side, and it actively raised funds in Shanghai, supporting Sun Yat-sen's crusade against Chen's military and boycotting Chen's fundraising activities in Shanghai (Chen 13). Therefore, the cohesion of Chaozhou Guild Hall of Shanghai roots in its social functions, and the guild hall is an important study object, which not only exert its influence in uniting the countrymen but also promoting the development of history.

The guild halls outside the Chaoshan area are the ideal lab for observing how the cultural identity of Chanshan people is strengthened and how the culture is transferred and maintained, but the guild halls within Chaoshan area are equal in importance. Shantou Guild Hall is a case in point. Its social functions reflect in the Chaoshan people's engagement into historical events. In the first decade of the 20th century, one of the biggest political events in Chaoshan area is the 1905 Chaoshan boycott against the U.S. treaty (Chen 11). In the 31st year of the reign of Emperor Guangxu (1905), China and the United States conducted contract negotiation on the access of Chinese laborers and the protection of the rights and interests of Chinese laborers in the United States. In response to the strong demand of overseas Chinese living in the United States, the Chinese government proposed to abolish the treaty and establish a new treaty, which was blatantly rejected by the United States government. As a result, a huge number of people in China refused to buy American goods and resisted 
the boycott movement against the United States. Since most of the overseas Chinese in the United States originated from Guangzhou, Xinning, Shantou and other places, the boycott movement was particularly fierce, attracting the attention of the Chinese. On May 4, Lingdong daily Newspaper of Shantou once published an article entitled with "Shantou Should Establish A Prohibition Against the United States", calling for the establishment of a prohibition against the United States. On May 13, it also published the report on the merchants of Shantou who wanted to win the movement, calling on all merchants in Shantou not to sell American goods. On May 23, hundreds of Shantou merchants gathered in the Wannianfeng guild hall, decided to respond to Shanghai, Guangzhou, the implementation of a boycott of the United States contract. Shantou businessmen to Wannianfeng Guild Hall as the gathering place, sending people to investigate the Shantou merchants to see if they sold the goods of the United States (Chen 11). Compared with the Chaozhou Guild Hall of Shanghai, the Wangnianfeng Guild Hall also have the function of calling on the fellows to engages into social events. The power and the way of may be different, but the unity function of the guild halls is apparent. According to the report of Lingdong Daily Newspaper in 1923, the Chaozhou Guild Hall of Shanghai also participated in the event, from which we can see that the local guild hall also has connection with the guild hall in other places.

\section{The Feature and Power of Oversea Chaozhou Guild Halls}

As a minority group in foreign countries, Chinese immigrants spontaneously rely on family and local relations to protect themselves and join business activities on the basis of mutual trust (Zhu 210). According to the theory of "differential mode of association" put forward by Fei Xiaotong, the interpersonal relationship among Chinese is centered on "oneself", which is like throwing a stone into the water, and the social relationship connected with others is not like the molecules in the group, but like the ripples of water, which are pushed out in circles and pushed further and further. From this perspective, the formation of overseas Chinese network is first of all due to the continuous migration of Chinese people to foreign countries and the network of relations. The functions of overseas Chaozhou guild halls are similar to those of domestic ones, but the assembly halls abroad emphasize more on education investment due to the fewer Chinese schools overseas. The earliest Chaozhou assembly hall abroad was probably the "Chaozhou company" founded in Malacca in 1822. It was renamed "Chaozhou Guild Hall" in 1882. In that year, the guild hall raised funds to rebuild the building which was donated by Chen Luohe (Gao 319). Chaozhou company was founded in the fifth year of the rule of Emperor Xianfeng (1855), which was the conclusion drawn by the board of directors and the construction committee of the association in May 2005 based on the analysis of the annual reports and archives of industrial land deeds and the colonies. At that time, the Chaozhou company, in collaboration with the group, initially acquired land at Shewei. Since then, it's industry has been expanded. In the first half of the 20th century, Penang Chinese society was in a transition period from an immigrant society to a settled society, and problems such as education, medical care and welfare arising from the social transformation were also pushing the local Chinese associations to timely adjust their structures to assume new social functions (Chen 30). Before 1861, the Chaozhou business group in Penang was still a loose community. However, the establishment of Hanjiang Family Temple in 1864 changed the internal division of Chaozhou gang. Hanjiang Family Temple is the predecessor of Penang Chaozhou Guild Hall and was established on the basis of Chaozhou company. However, in fact, "Hanjiang" is the largest river in Chaozhou prefecture. It originates in the mountainous area where Jiangxi, Fujian and Guangdong provinces meet. It was along this river that the Chaoshan people in eastern Guangdong, and the Hakka people in the western Fujian province sailed to the ocean. Thus, scholars believe that the intention of using "Hanjiang" to replace "Chaozhou" is to make the Chaozhou community internal differences caused by language fuzzier, and using "family" to replace "company" is intended to strengthen community integration through virtual blood ties and to enhance strength against the desire of the pressure from other side group (Chen 33). On the one hand, Hanjiang Family Temple constantly adjusts and improves its organization and power structure to strengthen its ethnic identity with Hanjiang Family Temple as the center of the Penang hipster community. On the other hand, a series of social engineering projects have been carried out to care for local hipsters, such as the establishment of hipster business office, Hanjiang villa, Hanjiang mutual aid association and Hanjiang school, etc., so as to enhance the cohesion of hipsters and strengthen the strength of ethnic groups (Chen 42-3). Similar to the Chaozhou Guild Hall of Shanghai, the Hanjiang Family Temple also undertakes the obligation to deal with the members' daily issues. The appearance of the name "marriage certificate" in 1941 was sufficient to indicate that the guild was performing a notary function that only the government could perform (Chen 49). The Chaozhou guild halls abroad also have the function of worshiping gods. Take Wanshian Temple (Chaozhou Guild Hall of Wanshian) as example. In the first half of the 19th century, the Chaoshan population in Wesleyan province established the Wanshian Temple with "Xuantian Emperor" as the center of belief in Jiaowan. The reason why the temples appeared overseas was that there were many risks in crossing the sea at that time. The immigrants took incense or gods with them for shelter, or they prayed for gods' protection before crossing the sea, and set up temples to thank god for his grace after their successful arrival. At the end of the Ming dynasty, Cai Hongjun, prayed to the "King of three mountains" when he was in danger (Ou 74). Being open to new things and to local culture and traditions is particularly important for Chaoshan merchants to establish and expand markets in overseas settlements. After all, it is impossible to succeed without understanding the market, and an open attitude is the source of innovation. It is no wonder that Chaoshan businessmen can get ahead of the trend and create a new situation in various fields. At the same time, local culture can be accepted by local people, which is the fundamental reason for Chaoshan people to establish and take root in other places and foreign countries ( $\mathrm{Ou} 75)$. The purpose of religious sacrificial activities is not only to recall the former sages, but also to gather the ethnic groups through dinner parties, so as to maintain a sense of belonging among them (Chen 55). Among the functional expenditures of Chaozhou guild halls, the expenditures of culture and education are obviously more than those of other categories. Chinese people have always 
attached great importance to the education of their children. As early as 1904, the Chinese in Penang established the first new Chinese school in southeast Asia, and many new schools were set up. Unwilling to be outdone, the Penang hipsters discussed the establishment of Hanjiang school on 10 October 1919, and the Penang Hanjiang school organizing office was established to raise funds for the school buildings (Chen 57). In the mid-18th century, Chaozhou people continued to pour into Thailand, working in agricultural plantations or in towns and cities. At the same time, tributary trade from southeast Asia to China resurfaced in the 18th century because the trade in the name of tribute was lucrative and often mediated by Chinese shipowners (Kuhn 97). In such an environment, the Chaozhou Guild Hall of Thailand also becomes one of the most important Chaoshan guild halls. The reason why Chaoshan people become the largest group of Thai Chinese, to a large extent, should be attributed to the special attention of Zheng Zhao when he was in office in attracting ancestral home folks (Gao 96). The leaders of the early Chinese communities were mainly from the merchant class. For example, before electing the leadership of Melaka Yinghe guild, it shall firstly investigate the shop and its operating conditions, and record the name of the shop and the owner as the reference basis for the election. Those who do not own shops or businesses will not be on the shortlist (Shi 176). The real reason why some of the early overseas Chinese in Malaysia were eager to become community leaders was that they were attracted by the power and status they held when they entered the leadership. Many wealthy overseas Chinese merchants in Singapore and Malaysia were moved and acted upon by the late Qing government's policy of selling government posts among the overseas Chinese. Being a leader of a community also shows that they have achieved a certain level of fame and status (Shi 177). According to the constitution of Chaozhou Guild Hall of Singapore, the purpose of the association is to connect with each other, promote friendship, mutual aid and public welfare, and promote education. Anyone who has attained the age of 21 years or above may join the association. He/she is deemed to be a member of the association if he/she completes a voluntary form and is recommended by one member and approved by one. If a member objects, it shall be approved by the board of directors before being deemed a member of the institute. Therefore, the guild halls at home and abroad both exert their cohesive force by developing their social functions, and the guild halls abroad keep paces with times since they manage to adopt new structure to unite the members. It is worth adding that both the guild halls at home and abroad have the function of worshiping the gods, which strongly unites the Chaoshan people since it is a part of Chaoshan culture.

\section{The Transformation of Guild Hall to Chamber of Commerce}

Chaozhou guild halls is the product of history, and they are now changed to be modern chamber of commerce, which helps to form a global network with the rapid development of Internet. Shortly after the foundation of the People's Republic of China, they all accepted the unified adaptation and leadership of the government and changed their names to the China federation of industry and commerce. In the market economy, the role of the chamber of commerce is becoming more and more important (Long 63). Looking from the nature, the chamber of commerce and industry is the organic combination of the gentry of origin, the official in Beijing and the tycoon of industry and commerce, which has the most strength and vitality among all kinds of halls (Duan 45). In the context of globalization, Chanshan businessmen have form a global network, and the greater the strength of human-centred transnational action and global linkages, the more likely local societies are to undergo social change (Sun 168). They build up chambers of commerce at home and abroad, which is listed on the official website of Chaoshan Businessmen. What is more, they publish their own magazine such as Chanshan Businessmen and International Chaoshan Express, in which supplies of studies are published. In addition, the Chanshan businessmen both at home and abroad attend Chaoshan International Convention every year. In addition, the Chaoshan International Convention's principles are listed below:

1) To unite fellow villagers, enhance friendship, promote culture, promote industry and commerce, serve the society, and seek common development.

2) To promote harmony between Teochew and other ethnic groups around the world and to create a better human civilization.

\section{3) The association is a non-profit making organization.}

The Chaoshan International Convention shares the same original intention but forms a bigger Chaoshan business group in the context of globalization. Chanshan businessmen now also organized vesting mission frequently to visit their fellows all over the world. Their connection is the epitome of social network in the context of globalization. They seem to cross cultural boundaries with strong cultural identification.

\section{Conclusion}

Chaoshan merchants, one of the most prestigious business groups in Chinese history, built up Chaozhou guild halls worldwide, and the constructions are significant sites that promote the historical progression. This essay argues that the construction of the Chaozhou guild halls root in Chaoshan people's idea of solidarity, but the power of intensifying Chanshan people's cultural identity lies heavily on the constructions' social functions, in that the daily life, decision, and action of Chaoshan merchants are made to associate with the place closely. This essay probes into a research topic that call for scrutiny and aims at contributing to the relevant discussion on the historical development and the cohesiveness of Chaozhou guild halls.

\section{References}

[1] Chen Haizhong, Huang Ting. Local Merchants, State Power and Modern Chaoshan Society[M]. Jinan University Press. 2013.

[2] Chen Jingxi, et al. Homeland and Strange Land: A Study of Chaoshan Society in Penang[M]. SDX Joint Publishing Company. 2016.

[3] Duan Bingren. Guild Hall[M]. Beijing Publishing House. 2006. 
[4] Gao Weinong. Overseas Chinese in S.E. Asia in the Qing Dynasty: An Updated Exploration of Transnational Migration, Economic Development, Community Evolution and Cultural Heritage[M]. Jinan University Press. 2014.

[5] Guo Xuyin. A Comparative Study between Chaoshan Businessman and Huizhou Businessman in Shanghai[J]. Modern China. 2013. 178-196.

[6] Kuhn, Philip A. Chinese Among Others: Emigration in Modern Times[M]. Jiangsu People's Publishing House. 2016.

[7] Long Shiyao, et al. The Origin and Evolution of Chanshan Merchants' Guild Hall[J]. Chaoshan Businessmen. 2018. 62-4.

[8] Ou Huailin, Wang, Yusheng. Chaoshan Merchants' Worship Economincs[J]. Chaoshan Businessmen. 2015. 70-5.

[9] Pan Junxiang, et al. A Brief History of Guild Hall in Shanghai[M]. Shanghai People's Publishing House. 2012.

[10] Shi Changjin. The Research of Chinese Associations in Malaysia[M]. Jinan University Press. 2013.

[11] Sun Jiaming, Lancaster, Scott. Chinese Globalization: A Profile of People-based Global Connection in China[M]. Routledge. 2013.

[12] Xue Liyong. Guild Halls in Shanghai in the Old Days[M]. Shanghai Bookstore Publishing House. 2015.

[13] Zhang Gengyi. The Decryption of Chaoshan Merchants' Developed Model[M]. Guangdong People's Publishing House. 2005.

[14] Zhu Dongqin, et al. On the Developments of Overseas Chinese Society from Multiple Perspectives[M]. Social Science Academic Press. 2018. 